\title{
Atypical folliculitis caused by Malassezia spp. in immunosuppressed patients
}

\author{
Eduardo Marín-Hernández ${ }^{*}$, Ciara G. Mejía-Mancera², Miguel A. Quijada-Henderson², and \\ Alfredo Valero-Gómez ${ }^{3}$ \\ ${ }^{1}$ Servicio de Dermatología Pediátrica, Unidad Médica de Alta Especialidad Hospital de Pediatría; ${ }^{2}$ Servicio de Dermatología, Unidad Médica de \\ Alta Especialidad Hospital de Especialidades; ${ }^{3}$ Servicio de Anatomía Patológica Pediátrica, Unidad Médica de Alta Especialidad Hospital de \\ Pediatría. Centro Médico Nacional Siglo XXI, Instituto Mexicano del Seguro Social, Mexico City, Mexico
}

\begin{abstract}
Background: Folliculitis due to Malassezia spp. (MF), caused mainly by Malassezia furfur, is clinically characterized by an acneiform eruption expressing follicular papules and pustules, predominantly on the trunk. Diagnosis of MF requires confirmation of the presence of yeasts in the hair follicle. The treatment of choice is topical or oral with azoles. We report two cases of folliculitis due to Malassezia spp. of atypical distribution in immunosuppressed patients. Case reports: Case 1. We describe a 14-year-old male patient diagnosed with chondroid osteosarcoma who required surgical treatment and chemotherapy. He was hospitalized for fever and neutropenia, presenting a rash of papulopustular lesions on the upper and lower extremities and neck. Direct examination and biopsy were performed to conclude the diagnosis of disseminated atypical Malassezia spp. folliculitis. Case 2. We describe a 16-year-old male patient diagnosed with synovial sarcoma, treated with surgical resection and chemotherapy. During hospitalization due to fever and neutropenia, he presented with disseminated dermatosis of the head, trunk, and upper extremities, showing multiple follicular papules and pustules with erythematous base; on the trunk, there were few lesions. In the supraciliary region, he showed erythema and furfuraceous desquamation. Direct examination of a follicle showed thick-walled round yeasts compatible with MF. Conclusions: MF is a frequent entity but of low diagnostic suspicion. Immunosuppressed patients may manifest atypical clinical characteristics in non-seborrheic areas, implying diagnostic difficulty. Biopsy and direct examination are essential to corroborate the etiology in patients with immunosuppression or with a non-classical presentation.
\end{abstract}

Keywords: Folliculitis. Malassezia. Atypical. Immunosuppression.

\section{Foliculitis atípica por Malassezia spp. en pacientes inmunosuprimidos}

\section{Resumen}

Introducción: La foliculitis por Malassezia spp., causada principalmente por Malassezia furfur, se caracteriza clínicamente por una erupción acneiforme, con pápulas y pústulas foliculares de predominio en el tronco. El diagnóstico requiere confirmar la presencia de las levaduras en el folículo piloso. El tratamiento de elección es tópico u oral con azoles. Se reportan dos casos de foliculitis por Malassezia spp. de distribución atípica en pacientes inmunosuprimidos. Casos clínicos: Caso

\section{Correspondence:}

*Eduardo Marín-Hernández

E-mail: emarinh1973@yahoo.com.mx

Available online: 24-01-2022

Date of reception: 26-03-2021

Date of acceptance: 06-07-2021

DOI: 10.24875/BMHIM.21000055
Bol Med Hosp Infant Mex. 2022;79(1):62-68 www.bmhim.com 1665-1146/C 2021 Hospital Infantil de México Federico Gómez. Published by Permanyer. This is an open access article under the CC BY-NC-ND license (http://creativecommons.org/licenses/by-nc-nd/4.0/). 
1. Paciente de sexo masculino de 14 años con diagnóstico de osteosarcoma condroide que ameritó tratamiento quirúrgico y quimioterapia. Fue hospitalizado por fiebre y neutropenia, presentando una erupción con lesiones papulopustulosas en las extremidades superiores e inferiores y en el cuello. Se realizaron examen directo y biopsia para concluir el diagnóstico de foliculitis por Malassezia spp. atípica diseminada. Caso 2. Paciente de sexo masculino de 16 años con diagnóstico de sarcoma sinovial, tratado con resección quirúrgica y quimioterapia, hospitalizado por fiebre y neutropenia. Presentó dermatosis diseminada en la cabeza, el tronco y las extremidades superiores, con múltiples pápulas y pústulas foliculares con base eritematosa; en el tronco había escasas lesiones. En la región supraciliar mostró eritema y escama furfurácea. Se realizó examen directo de un folículo, que reportó levaduras redondas de pared gruesa, compatibles con foliculitis por Malassezia spp. Conclusiones: La foliculitis por Malassezia spp. es una afección frecuente, pero de poca sospecha diagnóstica. En pacientes inmunosuprimidos puede manifestarse con una clínica atípica en áreas no seborreicas, lo que implica la dificultad del diagnóstico. La biopsia y el examen directo son fundamentales para corroborar la etiología en pacientes con inmunosupresión o con expresión no clásica.

Palabras clave: Foliculitis. Malassezia. Atípico. Inmunosupresión.

\section{Introduction}

Folliculitis due to Malassezia spp. (MF), formerly known as Pityrosporum folliculitis, was first described as an acneiform eruption related to broad-spectrum antibiotics. Subsequently, this disease was recognized as a condition with specific clinical and histologic features. It is currently defined as an infection of the hair follicle caused by yeasts of the genus Malassezia, mainly $M$. furfur. It affects adolescents and adults and is clinically characterized by an acneiform eruption, expressed by the presence of pruritic follicular papules and pustules located predominantly on the trunk ${ }^{1}$. It is necessary to confirm the presence of yeasts in the hair follicle by direct examination, culture, or histopathological study to diagnose MF. We report two cases of folliculitis due to Malassezia spp. with atypical distribution in immunocompromised patients.

\section{Clinical cases}

\section{Case 1}

We describe the case of a 14-year-old male patient diagnosed with chondroid osteosarcoma of the left proximal tibia, recently diagnosed with pulmonary metastases. He required amputation of the left extremity, complemented with ten cycles of chemotherapy based on cisplatin, epirubicin, cyclophosphamide, mesna, as well as prednisone and dexamethasone as premedication. The last reason for admission to our unit was fever, lymphopenia, and neutropenia. Blood cultures were performed with no bacterial development, and he was treated with piperacillin-tazobactam. Due to neutropenia, filgrastim $(300 \mu \mathrm{g})$ was prescribed every 24 hours for 7 days. Four days after the application of the neutrophil colony stimulant, the patient presented cutaneous eruption on the extremities, accompanied by discrete pruritus, for which the dermatology service was requested to discard a possible pharmacological reaction. Physical examination revealed a disseminated dermatosis, predominantly on the upper and lower extremities, and few lesions on the trunk and neck characterized by papules and some pustules on an erythematous base with follicular distribution (Figure 1). Another dermatosis was identified on the head, at the level of the cheeks and scalp, characterized by plaques consisting of erythema, furfuraceous desquamation, and some papules. The probable diagnosis of Sweet-like syndrome secondary to filgrastim versus folliculitis was proposed. The second dermatosis was diagnosed as seborrheic dermatitis. A forearm biopsy, a mycologic study of the face, and the pustular lesion on the neck were performed. Histology showed epidermis with orthokeratosis and irregular moderate acanthosis, identifying dilated follicles, mainly in the bulb and isthmus area, with the presence of a keratin plug and spherical microorganisms compatible with Malassezia yeasts (Figure 2). Mycological examination reported the presence of yeasts, and culture showed the presence of Malassezia. Based on the above, disseminated atypical folliculitis caused by Malassezia spp. and seborrheic dermatitis were diagnosed in an immunocompromised patient. Treatment with itraconazole (100 mg orally every 24 hours for 15 days) was prescribed; fever subsided on the third day of treatment with resolution of symptoms.

\section{Case 2}

We describe the case of a 16-year-old male patient diagnosed with left anterior brachial monophasic 


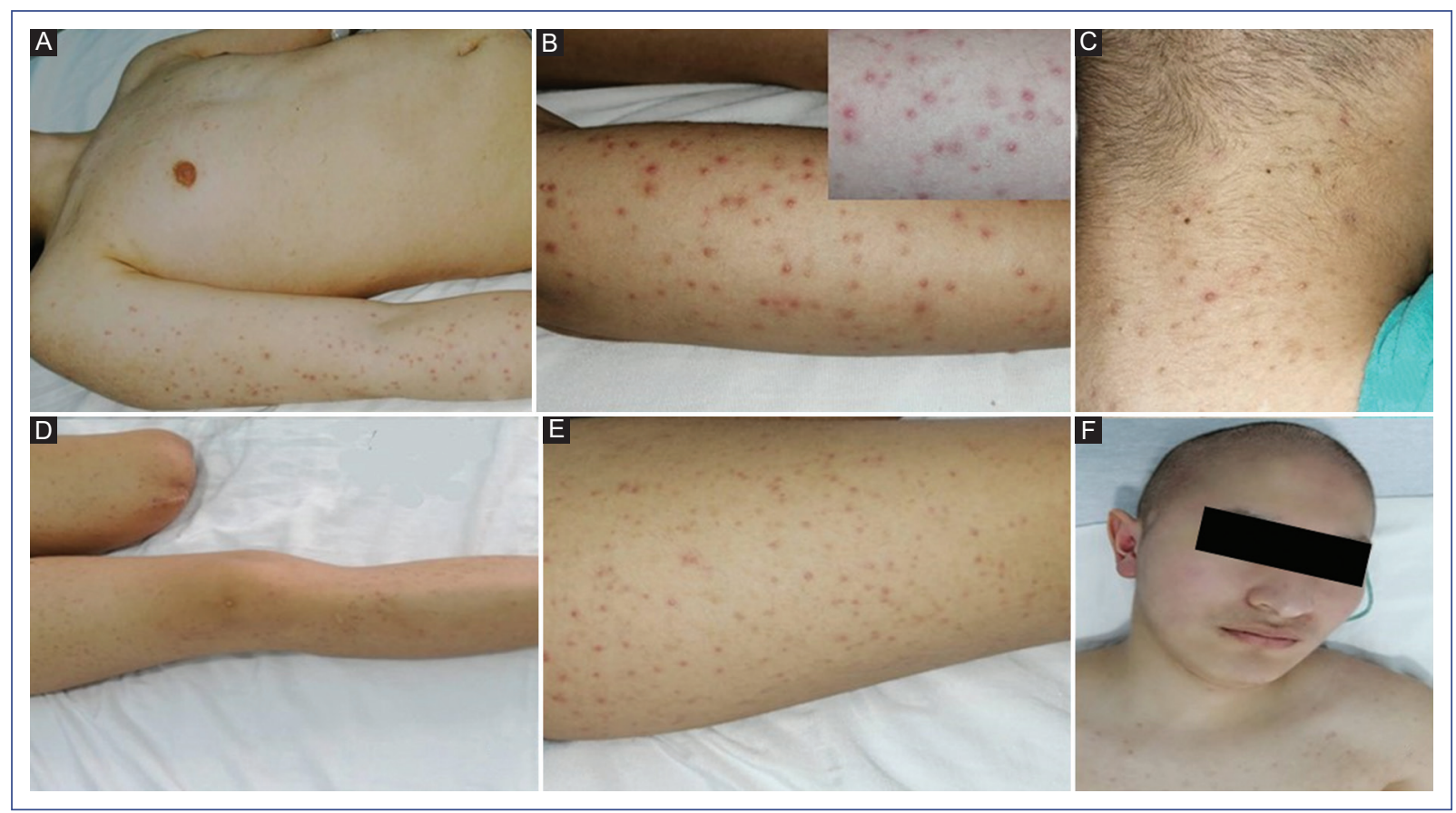

Figure 1. Dermatosis affects non-seborrheic areas with follicular distribution and papulopustular elements with an erythematous base. A. Arm and forearm. B. Close-up. C. Involvement of the posterior aspect of the neck. D. Multiple lesions on thighs and leg. E. Detail of follicular involvement. F. Erythema on cheeks and lower forehead with furfuraceous desquamation.

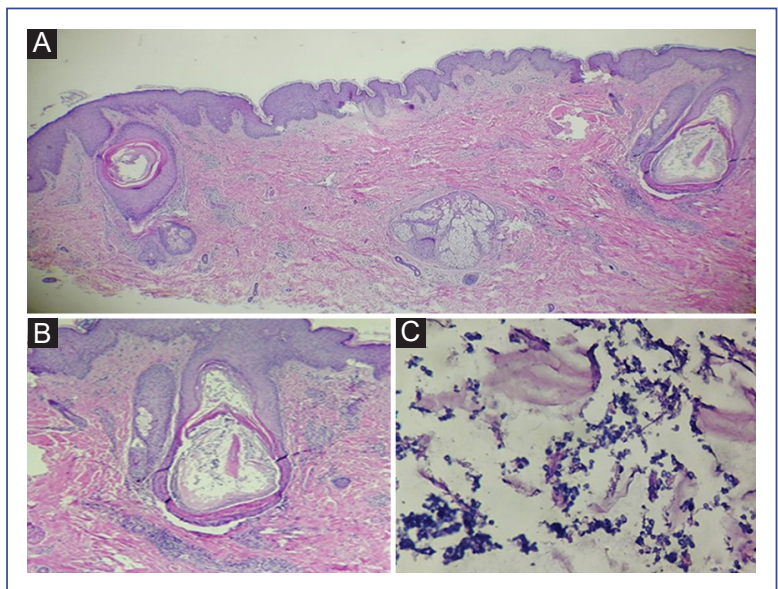

Figure 2. A. Panoramic view of the dilated follicles in the area of the bulb and isthmus. Hematoxylin-eosin stain (4X). B. Keratin plug with abundant Malassezia yeasts. Hematoxylin-eosin stain $(10 \mathrm{X})$. C. Detail of the yeasts. Hematoxylin-eosin stain (20X).

synovial sarcoma that required complete surgical resection and chemotherapy initiated 10 days before hospitalization due to fever and neutropenia. A study protocol was initiated with blood cultures, which showed no bacterial growth. The Infectious Diseases Department indicated treatment with piperacillin-tazobactam. Filgrastim (300 $\mu$ g every 24 hours) was prescribed to treat neutropenia. Subsequently, the patient presented with a disseminated dermatosis on the head and upper extremities, characterized by follicular papules and pustules with an erythematous base, affecting the head, cheeks, nose, and back of the neck, while the upper extremities, arms, forearms, and trunk showed few lesions. Another dermatosis was found on the face, particularly in the supraciliary region, characterized by erythema and furfuraceous squamous lesions. The patient had a history of juvenile acne, presenting open and closed comedones on the face (Figure 3). A direct examination with $10 \%$ potassium hydroxide of the pustule contents on the right arm was performed, reporting thick-walled round yeasts compatible with Malassezia; there was no yeast development in the blood culture. The patient was treated with itraconazole (100 mg orally every 24 hours for 15 days), with improvement on the third day and remission of fever.

\section{Discussion}

Folliculitis is a subacute inflammatory process affecting the pilosebaceous follicle. Clinically it manifests with 


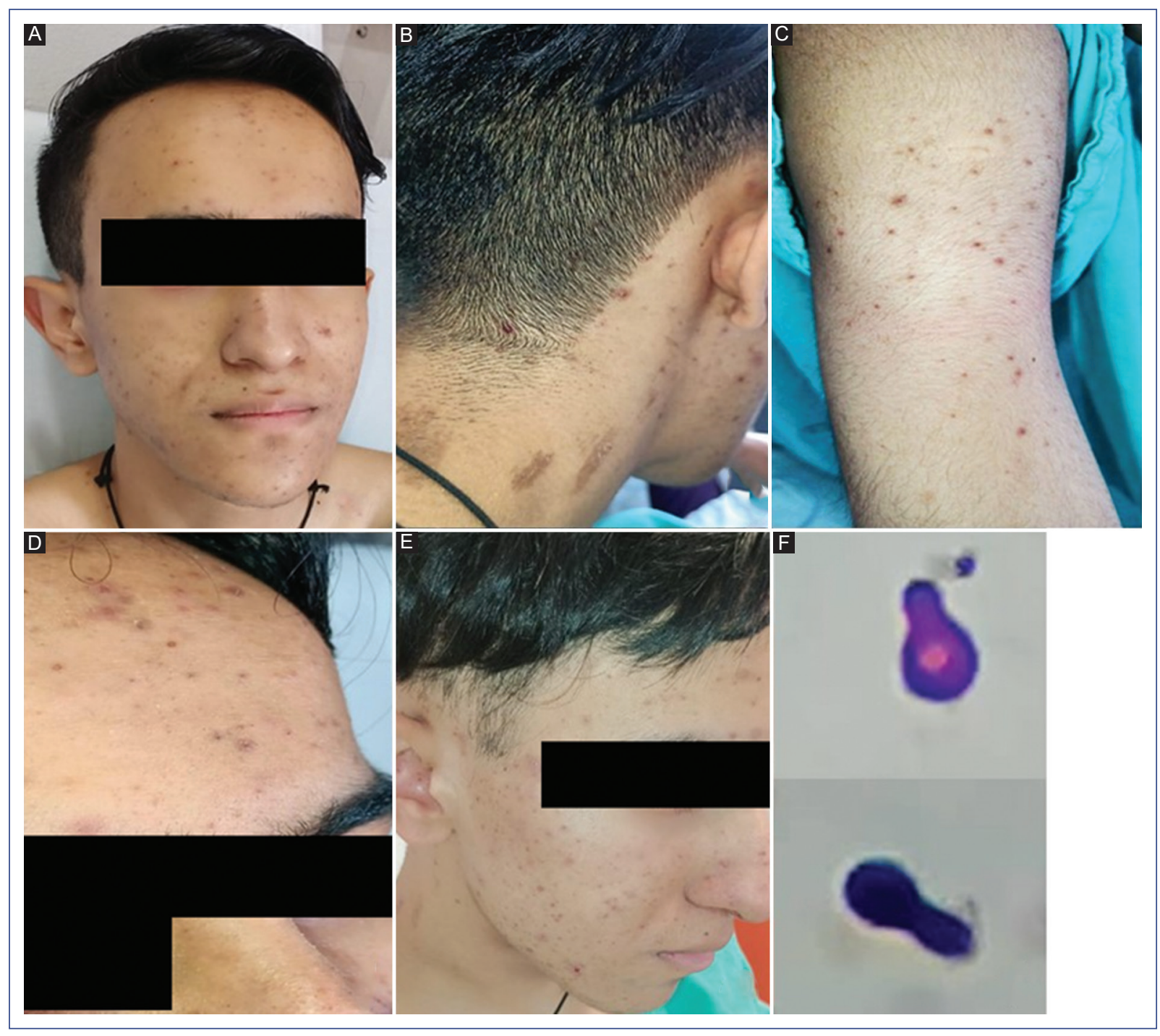

Figure 3. A. Dermatosis affects the face, forehead, cheeks, and nose with papulopustular follicular lesions with an erythematous base and some open and closed comedones. B. Neck with follicular involvement. C. Right arm. D. Closeup of the lower forehead with erythema and furfuraceous desquamation. E. Control at five days without fever. F. Close-up of a thick-walled round yeast corresponding to Malassezia.

papules or pustules in the follicular orifices, pruritic and located mainly on the trunk. It predominates in body regions with more pilosebaceous follicles. Among the most frequent agents are Staphylococcus aureus, Malassezia, Demodex, and Pseudomonas aeruginosa'.

The first description of the yeast Malassezia was made in 1846 by Eichstedt. In 1874, the French histologist and physiologist Louis-Charles Malassez pointed out its yeast nature and related it to the squamous lesions observed on the skin of the scalp. In 1889, Henri Baillon suggested the name Malassezia furfur in honor of the previous author due to the furfuraceous scales associated with seborrheic dermatitis ${ }^{2}$.
MF was first described by Weary et al. in 1969 as an acneiform eruption related to antibiotics. Subsequently, Potter et al. recognized it as a disease with specific clinical and histological features, caused by yeasts of the genus Malassezia spp., mainly M. furfur ${ }^{1}$. In patients with immunosuppression, the most frequent genera detected are $M$. globosa, $M$. restricta, and M. sympodialis $^{3}$.

The genus Malassezia currently includes 18 species, 11 found on human skin, and the rest in animals. $M$. restricta and $M$. globosa are the species most isolated from dermatological lesions and healthy skin as part of the microbiota ${ }^{4-7}$. Although the growth of this 
yeast is controlled thanks to the immune system ${ }^{5}$, it can also act as an opportunistic pathogen in dermatitis with inflammation (atopic dermatitis, folliculitis, and psoriasis) and without inflammation (pityriasis versicolor), being a potential reservoir of infections that could spread into the bloodstream ${ }^{6}$.

Malassezia is an opportunistic microorganism that transitions from the saprophytic to the mycelial phase, becoming pathogenic under certain conditions such as increased temperature, oily skin, sweating, and immunosuppression, which may be related to atypical and disseminated cases $^{1,5}$. Among the pathophysiological factors, Malassezia has a high keratolytic capacity and produces a lipoxygenase-type enzyme that generates lipid peroxides that can damage cell membranes and interfere with cellular activity. This yeast is found in the stratum corneum and hair follicle, where it uses its lipases and phospholipases to hydrolyze sebum triglycerides into free fatty acids for its source of nutritional lipids leading to its proliferation'.

Lipases produced by Malassezia are involved in colonization, proliferation, invasion, and persistence in the host. LIP1 was the first to be identified in M. furfur; between 9 and 14 were identified later, depending on the species. The activities of lipases and phospholipases vary according to the species and participate from skin diseases to fungemias, which are associated with high lipolytic levels and related to the lipophilic activity of Malassezia ${ }^{6}$. Moreover, this yeast metabolizes fatty acids, such as arachidonic and vaccenic acid, releasing azelaic acid as one of the metabolites. This acid inhibits the action of the enzyme dopa-tyrosinase, which blocks the conversion of tyrosine to melanin, leading to the development of hypochromic spots. Histopathological studies of the skin of the affected areas reveal the presence of smaller melanosomes than those found in normal skin?

MF affects young and middle-aged adults and rarely children as they are usually immunocompetent individuals. Worldwide, the male-to-female ratio is $1: 1^{3}$. However, in Mexico, a ratio of 3:1 was reported, with an average age of 21 years. The most frequent topography in this series of MF cases was the trunk (94.6\%), followed by the face $(16.1 \%)$, neck $(12.5 \%)$, upper extremities (10.7\%), and lower extremities (3.6\%) Classically, the symptoms are similar to acneiform dermatitis, characterized by erythematous dome-shaped papules with a central pore and some very pruritic follicular pustules, although they may sometimes be asymptomatic. In severe cases, nodules and cysts may be observed in areas with many sebaceous glands, such as the scalp, face, trunk, and proximal upper extremities $^{6}$. Tsai et al. reported a case series of MF and described the concept of atypical variant when the distribution of lesions was in non-seborrheic areas with papule-like lesions and smaller follicular pustules, macules with predominance on the face, scalp, trunk, and lower extremities. In this study, $23 \%$ of the cases had different diagnostic suggestions as varied as pityriasis lichenoides, similar to prurigo for the lesions of the trunk and extremities, eosinophilic folliculitis, and rosacea on the face, finally integrating the diagnosis through biopsy $^{4,8}$.

MF is occasionally seen in certain immunosuppressed states such as diabetes mellitus, hematologic malignancies, bone marrow and solid organ transplantation, Hodgkin's disease, and human immunodeficiency virus (HIV) infection.

The presence of yeasts in the hair follicle must be confirmed by direct examination, culture, or histopathological study to diagnose $\mathrm{MF}^{9}$. Fungemia or Malassezia sepsis is one of the fatal complications of infection by this yeast. This complication has been described most frequently in preterm neonates and is related to catheter infection and parenteral nutrition. The clinical picture includes nonspecific signs and symptoms such as fever and respiratory distress; less frequent signs and symptoms include bradycardia, lethargy, hepatomegaly, splenomegaly, seizures, and cyanosis. Moreover, it can cause pneumonia and peritonitis in patients on peritoneal dialysis ${ }^{10}$. Malassezia-related fungemia remains largely underdiagnosed, probably because of the difficulties in isolating this yeast species due to its dependence on lipids for growth. The species commonly implicated in fungemia are $M$. furfur and M. pachydermatis ${ }^{6}$.

The histopathological findings that have been recognized are partial destruction of the hair follicle with the presence of abundant Malassezia yeasts and a perifollicular inflammatory infiltrate formed by neutrophils and lymphocytes ${ }^{6}$. An unusual histopathologic variant is necrotizing infundibular crystalline folliculitis, whose pathognomonic features are birefringent urate crystals represented as Alcian blue-positive filamentous mucinous material. On electron microscopy, this crystalline material is composed of broken tonofilaments embedded in an amorphous matrix ${ }^{11}$.

For direct examination, it is recommended to sample papules or pustules from three different sites with a blackhead remover and apply 10\% potassium hydroxide with Parker's ink to observe thick-walled round yeasts. Scales have been proposed to quantify the 
presence of yeasts on both direct examination and histopathology. The scales can be used as an easily accessible diagnostic tool to initiate appropriate treatment in a timely manner ${ }^{6}$.

Malassezia fungemia is underdiagnosed due to the low specificity and sensitivity of different blood culture systems used for diagnosis, the lack of standardization of in vitro antifungal susceptibility testing, and the lack of studies investigating drug resistance phenomena in these yeasts ${ }^{6}$.

In immunosuppressed patients, lesions may spread and be accompanied by fever ${ }^{1}$, so it is essential to differentiate Malassezia spp. folliculitis from skin lesions caused by hematogenous dissemination of Candida spp., acneiform eruption induced by drugs and bacterial infections, and acne ${ }^{12}$. Among the differential diagnoses in the cases described, the first is eosinophilic pustular folliculitis, consisting of recurrent outbreaks of highly pruritic plaques of circinate morphology formed by sterile follicular papules and pustules tending to centrifugal progression and central involution. The preferred distribution of lesions is on the face, trunk, and upper extremities; biopsy reveals an infiltrate of eosinophils and neutrophils in both the infundibulum and sebaceous gland, with good response to treatment with oral and topical corticosteroids $^{13}$.

Another differential diagnosis to consider is acneiform dermatitis. From the clinical point of view, acne and acneiform reaction can be distinguished by the absence of comedones in the former, and when they co-occur, acne usually affects the face ${ }^{14}$.

Drug-associated dermatoses should also be ruled out because of the colony-stimulating factor (G-CSF), as it is commonly used to treat myelosuppression triggered by chemotherapy. This pathology is described with sudden onset of urticarial plaques, painful purplish erythematous nodules, and disseminated papules on the head, neck, and trunk. Once the drug administration is suspended, there is a rapid improvement of the symptoms ${ }^{15}$. Although the association of G-CSF with Sweet's syndrome is known, it is not yet widely recognized. In analyzing the reported case, the use of G-CSF four days before the onset of dermatosis made us consider this possibility. Since the clinical presentation was atypical, with the histopathological study without evidence of neutrophil infiltrate, this association was ruled out ${ }^{16}$.

The treatment of choice for MF is topical antifungals, mainly azoles such as clotrimazole $1 \%$, bifonazole $1 \%$, ketoconazole $2 \%$, fenticonazole $2 \%$, tioconazole $1 \%$, and terbinafine $1 \%$ solution, all of which are suitable for localized skin lesions. In disseminated skin disease and systemic involvement, oral drugs such as ketoconazole $(200 \mathrm{mg} /$ day for 1-2 weeks), itraconazole (200 mg/day for 2 weeks), and fluconazole (150 mg/week for 4 weeks) are recommended, as they provide cure rates of up to $97 \%$. Other drugs used successfully are selenium sulfide $2.5 \%$, zinc pyrithione shampoo, and ciclopirox olamine $1 \%$ solution. Systemic treatment in MF is indicated in patients with immunosuppression or risk factors for complications $^{10}$.

The cases described corresponding to patients in middle adolescence were immunosuppressed due to treatment of their underlying pathology. These patients were hospitalized to control fever and neutropenia, developing a rash of disseminated papulopustular lesions on the upper and lower extremities and neck. Due to the non-classical clinical presentation, the presence of Malassezia-type yeast infection should be excluded. As an important antecedent, we recognized the presence of seborrheic dermatitis on the face or scalp, with the possibility that inflammation at these sites combined with immunosuppression was the starting point for dissemination in these atypical presentations. In both cases, hospital admission was due to neutropenia and fever, blood cultures were negative, and there was a poor response to broad-spectrum antibiotics. The possible lack of specificity of the blood cultures, plus the excellent response once antifungal treatment was initiated, allowed us to consider the possibility that the patients may have had subclinical fungemia.

We consider it necessary to report these cases, primarily because of the age at presentation, the location of the disseminated dermatosis predominantly in non-seborrheic sites, the presence of facial seborrheic dermatitis, and the fact that the patients were immunosuppressed due to the treatment of their underlying disease. This type of case raises the need to report the division of classic and atypical presentations according to the clinical manifestations ${ }^{4,8}$. The first is in those patients whose cutaneous expression is in seborrheic areas such as the trunk, face, and scalp with numerous papulopustular elements. The second in those patients with immunosuppression, fever, and intense pruritus, with lesions predominating in non-seborrheic areas such as upper and lower extremities, neck, paucipapular, showing the difficulty in diagnosing the disease. Also, the importance of biopsy and direct examination in this type of case to 
corroborate the etiology is emphasized, which reduces the possibility of adverse effects due to inadequate therapies in patients who already have complications. Finally, not having found a previous report with similar characteristics in Mexico in the pediatric medical literature suggests that this type of case may be underdiagnosed.

\section{Ethical disclosures}

Protection of human and animal subjects. The authors declare that no experiments were performed on humans or animals for this study.

Confidentiality of data. The authors declare that they have followed the protocols of their work center on the publication of patient data.

Right to privacy and informed consent. The authors have obtained the written informed consent of the patients or subjects mentioned in the article. The corresponding author has this document.

\section{Conflicts of interest}

The authors declare no conflict of interest.

\section{Funding}

None.

\section{References}

1. Rubenstein RM, Malerich SA. Malassezia (Pityrosporum) folliculitis. $\mathrm{J}$ Clin Aesthet Dermatol. 2014;7:37-41.

2. Padilla-Desgarennes MC. Pitiriasis versicolor. Dermatol Rev Mex. 2005;49:157-67.

3. Harada K, Saito M, Sugita T, Tsuboi R. Malassezia species and their associated skin diseases. J Dermatol. 2015;42:250-7.

4. Vlachos C, Henning MAS, Gaitanis G, Faergemann J, Saunte DM. Critical synthesis of available data in Malassezia folliculitis and a systematic review of treatments. J Eur Acad Dermatol Venereol. 2020;34:1672-83.

5. Pedrosa AF, Lisboa C, Gonçalves RA. Malassezia infections: a medical conundrum. J Am Acad Dermatol. 2014;71:170-6.

6. Rhimi W, Theelen B, Boekhout T, Otranto D, Cafarchia C. Malassezia spp. yeasts of emerging concern in fungemia. Front Cell Infect Microbiol. 2020;10:370.

7. Barrón HYL, Atoche DC, Eljure LN, Vega MME. Foliculitis por Malassezia spp.: características clínicas y epidemiológicas de pacientes del Centro Dermatológico de Yucatán. Sci Fungorum. 2018;47:67-71.

8. Tsai YC, Wang JY, Wu YH, Wang YJ. Atypical clinical presentations of Malassezia folliculitis: a retrospective analysis of 94 biopsy-proven cases. Int J Dermatol. 2018;57:e19-20.

9. Cabello I, Cermeño VJR. Foliculitis por Malassezia spp. en un paciente inmunocomprometido. Dermatol Venez. 2004;42:18-20.

10. Lagos A, Armas A, Ponce-Olivera RM, Araiza J, Bonifaz A. Foliculitis por Malassezia globosa en un paciente críticamente enfermo. Rev Mex Dermatol. 2014;58:465-70.

11. Saxer-Sekulic N, Vion-Gauthey B, Kaya G. Necrotizing infundibular crystalline folliculitis: a case report of an exceptional lesion of unknown etiology. Dermatopathology (Basel). 2014;1:3-6.

12. Nair SP, Gomathy M, Kumar GN. Disseminate and recurrent infundibulofolliculitis in an Indian patient: a case report with review of literatura. Indian Dermatol Online J. 2017;8:39-41.

13. Rodríguez-Díaz E, Junquera Llaneza ML, Nosti Martínez D, Barrio FA, Prado D'Almeida L, Martínez Merino A. Foliculitis pustulosa eosinofílica (enfermedad de Ofuji): respuesta al interferón alfa 2b. Actas Dermosifiliogr. 2001;92:233-8.

14. Estrada-Chávez G, Chávez-López MG, Estrada-Castañón RA. Severe acneiform dermatitis associated with the misuse of topical corticosteroids. Dermatol Rev Mex. 2018;62:301-5.

15. Paydas S, Sahin B, Seyrek E, Soylu M, Gonlusen G, Acar A, et al. Sweet's syndrome associated with G-CSF. Br J Haematol. 1993;85:191-2.

16. Kaya Z, Belen FB, Akyürek N. Granulocyte colony-stimulating factor induced Sweet's syndrome following autologous transplantation in a child with relapsed acute myeloblastic leukemia. Indian $\mathrm{J}$ Hematol Blood Transfus. 2014;30:376-8. 